\title{
Haloperidol 2 mg impairs inhibition but not visuospatial attention
}

Citation for published version (APA):

Logemann, H. N. A., Bocker, K. B. E., Deschamps, P. K. H., van Harten, P. N., Koning, J., Kemner, C., Logemann-Molnar, Z., \& Kenemans, J. L. (2017). Haloperidol $2 \mathrm{mg}$ impairs inhibition but not visuospatial attention. Psychopharmacology, 234(2), 235-244. https://doi.org/10.1007/s00213-016-4454-z

Document status and date:

Published: 01/01/2017

DOI:

10.1007/s00213-016-4454-z

Document Version:

Publisher's PDF, also known as Version of record

Document license:

Taverne

Please check the document version of this publication:

- A submitted manuscript is the version of the article upon submission and before peer-review. There can be important differences between the submitted version and the official published version of record.

People interested in the research are advised to contact the author for the final version of the publication, or visit the DOI to the publisher's website.

- The final author version and the galley proof are versions of the publication after peer review.

- The final published version features the final layout of the paper including the volume, issue and page numbers.

Link to publication

\footnotetext{
General rights Owners
rights.

- You may freely distribute the URL identifying the publication in the public portal. please follow below link for the End User Agreement:

www.umlib.nl/taverne-license

Take down policy

If you believe that this document breaches copyright please contact us at:

repository@maastrichtuniversity.nl

providing details and we will investigate your claim.
}

Copyright and moral rights for the publications made accessible in the public portal are retained by the authors and/or other copyright owners and it is a condition of accessing publications that users recognise and abide by the legal requirements associated with these

- Users may download and print one copy of any publication from the public portal for the purpose of private study or research.

- You may not further distribute the material or use it for any profit-making activity or commercial gain

If the publication is distributed under the terms of Article $25 \mathrm{fa}$ of the Dutch Copyright Act, indicated by the "Taverne" license above, 


\title{
Haloperidol 2 mg impairs inhibition but not visuospatial attention
}

\author{
H.N. Alexander Logemann ${ }^{1,2}$ • Koen B.E. Böcker ${ }^{3}$ Peter K.H. Deschamps ${ }^{4}$. \\ Peter N. van Harten ${ }^{5,6}$ • Jeroen Koning ${ }^{7}$. Chantal Kemner ${ }^{4}$. \\ Zsófia Logemann-Molnár ${ }^{8}$ • J. Leon Kenemans ${ }^{1}$
}

Received: 18 April 2016 / Accepted: 28 September 2016 / Published online: 17 October 2016

(C) Springer-Verlag Berlin Heidelberg 2016

\begin{abstract}
Rationale The dopaminergic system has been implicated in visuospatial attention and inhibition, but the exact role has yet to be elucidated. Scarce literature suggests that attenuation of dopaminergic neurotransmission negatively affects attentional focusing and inhibition. To the best of our knowledge, this is the first study that evaluated the effect of dopaminergic antagonism on stopping performance.

Methods Dopaminergic neurotransmission was attenuated in 28 healthy male participants by using $2 \mathrm{mg}$ haloperidol. A repeatedmeasures placebo-controlled crossover design was implemented, and performance indices of attention and inhibition were assessed in the visual spatial cueing task (VSC) and stop signal
\end{abstract}

H.N. Alexander Logemann

h.n.a.logemann@gmail.com

1 Helmholtz Research Institute, Department of Experimental Psychology, Utrecht University, P.O. Box 80140, 3508 TC, Utrecht, The Netherlands

2 Institute of Psychology, Eötvös Loránd University, Budapest, Hungary

3 Alan Turing Insitute Almere, Louis Armstrongweg 84, 1311 RL, Almere, The Netherlands

4 Department of Psychiatry, Brain Center Rudolf Magnus, University Medical Center Utrecht, Heidelberglaan 100, 3584 CX Utrecht, The Netherlands

5 Department of Psychiatry and Psychology, Maastricht University Medical Centre, Maastricht, The Netherlands

6 Psychiatric Centre GGZ Centraal, Amersfoort, The Netherlands

7 Psychiatric centre Pro Persona, Siependaallaan 3, 4003 LE Tiel, The Netherlands

$8 \quad$ Adapting Minds, Databankweg 12, 3821

AL Amersfoort, The Netherlands task (SST). Additionally, the effect of haloperidol on motoric parameters was assessed. It was expected that haloperidol as contrasted to placebo would result in a reduction of the "validity effect," the benefit of valid cueing as opposed to invalid cueing of a target in terms of reaction time. Furthermore, an increase in stop signal reaction time (SSRT) in the SST was expected. Results and conclusion Results partially confirmed the hypothesis. Haloperidol negatively affected inhibitory motor control in the SST as indexed by SSRT, but there were no indications that haloperidol affected bias or disengagement in the VSC task as indicated by a lack of an effect on RTs. Pertaining to secondary parameters, motor activity increased significantly under haloperidol. Haloperidol negatively affected reaction time variability and errors in both tasks, as well as omissions in the SST, indicating a decreased sustained attention, an increase in premature responses, and an increase in lapses of attention, respectively.

Keywords Dopaminergic $\cdot$ Dopamine $\cdot$ Haloperidol Inhibition $\cdot$ Attention $\cdot$ Motor activity

\section{Introduction}

The dopaminergic (DA) neurotransmitter system has been implicated in (visuospatial) attention and inhibition; however, the exact role remains to be elucidated. Visuospatial attention has been investigated by using the visual spatial cueing task (Posner et al. 1980). In this task, a cue signals the likely location of an upcoming target presented in either the left or right visual field, to which a response is required. In a minority of trials, the target is invalidly cued, that is, presented in the location opposite to the cued location. The relevant outcome is the "validity effect." The validity effect reflects the benefit in terms of reaction time to responses to validly cued targets as compared to invalidly cued targets. The validity effect is 
thought to reflect two mechanisms: bias, referring to the neuronal signals that modulate the sensitivity of sensory cortex, and disengagement, the decoupling of attention from an invalidly cued location (Corbetta and Shulman 2002; Corbetta et al. 2008). Simplified, a large validity effect can indicate relatively enhanced bias and/or reduced disengagement (rigidity). A small validity effect, on the other hand, can reflect relatively diminished bias and/or enhanced disengagement (distractibility).

Conceptually, disengagement is linked with inhibition as it also plays a role when an ongoing response suddenly has to be inhibited because of a sudden change in task demands. This situation is captured by the stop signal task (SST) (Logan et al. 1984; de Jong et al. 1990). In this task, go stimuli are presented and in a minority of trials are followed by a stop stimulus. The stop stimulus signals to withhold a planned response. The relevant outcome measure is the stop signal reaction time (SSRT), an index of inhibition (de Jong et al. 1990; De Jong et al. 1995).

There is conceptual overlap between inhibition and disengagement. Studies show some support for this link. Electrophysiological studies show that stop signals in the SST elicit a positivity of about $300 \mathrm{~ms}$ latency (P300) that is modulated by success of stopping (Lansbergen et al. 2007); this modulation reflects inhibitory-related activity presumably within the superior frontal gyrus (SFG) (Kenemans and Kähkönen 2011). Targets in the VSC task elicit a late positive deflection (LPD) that is larger for invalidly cued targets as opposed to validly cued targets (Mangun and Hillyard 1991; Meinke et al. 2006). This could mean that the LPD is larger when the specific stimulus requires a disengagement of attention. It has been speculated that the source of the LPD reflects activity within the temporal parietal junction (Logemann et al. 2013). Mangun and Hillyard (1991) argued that part of the LPD as evidenced in the VSC paradigm probably consists of the P300. It is plausible that, although the exact neuroanatomical substrates may differ, LPD and stop P300 do share an intracranial generator. Furthermore, pharmacological effects of enhancement of the cholinergic system on disengagement mirror those on inhibition. Firstly, studies show that nicotine, a cholinergic agonist, reduces the validity effect (Witte et al. 1997; Thiel et al. 2005; Meinke et al. 2006; Vossel et al. 2008). This reduction of the validity effect was found to be a result of faster responses in invalid trials (Witte et al. 1997; Meinke et al. 2006; Thiel and Fink 2008) and possibly reflect enhanced disengagement. Secondly, for groups with enough room for improvement, nicotine decreases the SSRT, indicating improvement of inhibition (Potter et al. 2012).

Effects of manipulating noradrenergic neurotransmission on visuospatial attention have also been investigated. Coull et al. (2001) reported a decrease of the validity effect for stimuli presented in the left visual field (LVF) in response to clonidine (which effectively attenuates noradrenergic neurotransmission). As the authors note, the validity effect is in general larger for stimuli presented in the left versus right visual field as a potential result of hemispheric lateralization of attentional processing. As such, a potential drug effect is more likely to be detected for stimuli presented in the LVF. Also, as Coull et al. (2001) note, processing of stimuli presented in the LVF may be more sensitive to disruptions.

The reduction of the validity effect may imply a reduction of bias but could also entail an increase in disengagement. Importantly, in the same study, fMRI data showed a reduction of parietal activity in the right hemisphere during spatial orienting in response to clonidine, supporting the notion of reduced bias due to the clonidine challenge.

In line with these results, clonidine has also been reported to negatively affect the electrophysiological index of bias (Logemann et al. 2014). In the latter study, clonidine reduced the target-related N1 modulation by validity of cueing, albeit in a subsample. Hence, noradrenergic neurotransmission may be primarily related to bias, and cholinergic neurotransmission seems to be related to disengagement and related inhibition.

Finally, for the relation between dopaminergic neurotransmission and bias, Clark et al. (1989) reported that dopaminergic antagonism by droperidol resulted in a reduction of the validity effect. While at first sight this points to a specific effect of enhanced disengagement, it can also be explained as a reducing effect on bias. Importantly, a direct evaluation of the role of dopamine in disengagement and inhibition is still lacking. However, genetic (Gurvich and Rossell 2014), animal (Bari et al. 2009; Eagle et al. 2011; Bari and Robbins 2013), and pharmacological studies with human subjects (Lijffijt et al. 2006; Overtoom et al. 2009) suggest a link between dopamine and inhibition, although relatively recent animal studies yielded seemingly conflicting results. Pertaining to the latter, it has been suggested that affecting dopaminergic neurotransmission with either blockade of the dopamine transporter (DAT) or direct (ant)agonism of any of the D1-D4 receptors does not affect SSRT in male Lister hooded rats (Bari et al. 2009; Bari and Robbins 2013). However, Eagle et al. (2011) showed that dopaminergic antagonism, using sulpiride directly infused into the dorsomedial striatum, does negatively affect SSRT but argue that this effect is region and receptor dependent.

In humans, dopamine has been (indirectly) linked to inhibition. Patients with attention deficit/hyperactivity disorder (ADHD), which is marked by deficits in attention and inhibition (Kenemans et al. 2005), show reduced D2/D3 receptors in the striatum (Volkow et al. 2009). Furthermore, it has been shown that striatal D2/D3 availability is associated with response inhibition (Ghahremani et al. 2012). Preliminary results point toward a potential link between this striatal D2/ D3 availability and activation within the right inferior frontal gyrus (rIFG; Ghahremani et al. 2012), a region strongly implicated in inhibitory processing (Corbetta and Shulman 2002; Corbetta et al. 2008; Aron et al. 2014; Kenemans 2015). 
Indeed, the effects of indirect manipulations of dopaminergic neurotransmission in human subjects also point toward a link between dopamine and inhibition. With respect to diet, it has been shown that administration of tyrosine (a precursor to dopamine, but also to noradrenaline) supplements results in shorter SSRTs in healthy female participants (Colzato et al. 2014). Also, enhancing dopaminergic neurotransmission by blockage of DAT via methylphenidate has been shown to shorten SSRTs in adults with ADHD (Overtoom et al. 2009). Furthermore, dopamine metabolite levels do correlate significantly with SSRT, but not with reaction time (RT) to go stimuli (Lijffijt et al. 2006). Of note, in the same study, the reverse pattern was found for norepinephrine metabolite levels. With reference to the aforementioned studies, it must be stressed however that methylphenidate also affects noradrenergic (NE) neurotransmission, complicating specific attribution of effects (Zetterström et al. 1988). To the best of our knowledge, a direct evaluation of the effect of dopaminergic antagonism on stopping performance is still lacking. In sum, dopaminergic attenuation may compromise bias as well as disengagement and inhibition.

In the current study, dopaminergic neurotransmission was attenuated by using $2 \mathrm{mg}$ haloperidol, and the effect on performance indices of bias, disengagement, and related inhibitory control was assessed in the VSC and SST, respectively. To account for individual variability with respect to the drug response, the drug effect on motoric parameters was used as a proxy for central responsivity. It was hypothesized that $2 \mathrm{mg}$ haloperidol relative to placebo would decrease the validity effect in the VSC task and would increase SSRT in the SST.

\section{Methods}

\section{Participants}

Thirty-five healthy male students were recruited from Utrecht University. All participants gave informed consent prior to participation. It was required to pass a short medical interview prior to the experiment. In total, 28 subjects, ranging from 20 to 33 years of age $(M=23, \mathrm{SD}=3)$, completed the study. Two participants could not participate due to potential health concerns. Four participants withdrew from the study for reasons unrelated to the pharmacological manipulation. One participant withdrew because of side effects. The study was approved by the Medical Ethics Committee from the University Medical Center Utrecht and conducted in accordance with the Declaration of Helsinki.

\section{Pharmacological manipulation}

Haloperidol is a potent dopamine D2 receptor antagonist (Kapur et al. 2000). It also has affinity for the alpha-1 adrenoreceptor, which is however about a factor of 13 lower than that for the D2 receptor (Richelson and Nelson 1984; Leysen et al. 1992; Schotte et al. 1996; Kroeze et al. 2003). Both $2 \mathrm{mg}$ haloperidol and placebo were encapsulated (DB capsule, AA Swedish orange). The placebo contained no active substance and consisted of a mixture of lactose monohydrate DC and magnesium stearate $(0.5 \%)$.

\section{Tasks}

\section{Visual spatial cueing task}

Our specific implementation of the VSC task was a combination of the VSC task as described in van der Lubbe et al. (2006) and the task as described in Mangun and Hillyard (1991). Trials always started with a fixation dot, presented for $600 \mathrm{~ms}$, after which a cue was presented for $400 \mathrm{~ms}$. The cue consisted of a diamond (width $1.3^{\circ}$, height $0.7^{\circ}$ ) for which the left and right half differed in terms of color (red versus green). In each block of trials, either the green or the red arrow-shaped half indicated the most likely location of the subsequent target stimulus and therefore could be used to direct attention (see below). The cue was followed by the fixation dot (presented again for $600 \mathrm{~ms}$ ) and subsequently by one of two possible targets, either a short white bar (width $0.8^{\circ}$, height $2.0^{\circ}$ ) or a long white bar (width $0.8^{\circ}$, height $2.4^{\circ}$ ), presented in either the left or right visual hemifield $\left(6.4^{\circ}\right.$ from the center of the screen) for $100 \mathrm{~ms}$. Subsequently, the fixation dot was presented for $1400 \mathrm{~ms}$. The total duration of one trial was $3100 \mathrm{~ms}$. A pretreatment ("pretest") version consisted of two blocks in total, and an instruction was presented prior to each block. The first block was used as a practice block and consisted of 32 trials of which 8 were invalid trials. Valid trials were trials in which the location of the target was congruently cued (target presented at location indicated by the cue); invalid trials were trials in which the location of the target was opposite to the location indicated by the cue. The second block was used for data analysis and consisted of 256 trials of which $75 \%$ were valid trials. The posttreatment ("posttest") version consisted of in total four blocks (no practice block), which differed with respect to the specific stimulus-response assignment and color-cue assignment. The posttest started with the block equal to the block of the pretest in terms of the stimulusresponse and color-cue assignment. Within blocks, trials were semi-randomized for each task run and specific block order was counterbalanced across participants.

\section{Stop signal task}

An SST similar to Schmajuk et al. (2006) was implemented. In this task, go stimuli were presented centrally, randomly, sequentially, and slightly above a fixation cross. These stimuli consisted of the letters $\mathrm{X}$ (height and width $1.4^{\circ}$ ) and $\mathrm{O}$ (height 
$1.4^{\circ}$ and width $1.3^{\circ}$ ), and a differential response was required after presentation of these stimuli (left or right button press). In $25 \%$ of trials in a stop signal block, the go stimulus was followed by a stop stimulus (letter " $\$$ ", height $1.7^{\circ}$, width $0.8^{\circ}$ ) which signaled that the go response should be withheld. All three stimuli were presented for $150 \mathrm{~ms}$, and trial durations varied between 1.5 and $1.8 \mathrm{~s}$. The pretest consisted of 126 go trials (no stop trials), a base stop signal block (used to estimate the optimal stimulus onset asynchrony (SOA) to yield $50 \%$ inhibitions in a subsequent block), and lastly two experimental stop signal blocks (for data analysis, 128 trials in each block). Since participants often delay responding to go stimuli in stop signal blocks, participants were instructed to speed up responding to go stimuli in stop signal blocks if the average reaction time to go stimuli in these blocks was more than 1.5 times the reaction time in the first block (block without the stop trials). In the base stop signal block, the go-stop stimulus interval was set at $250 \mathrm{~ms}$, and in subsequent blocks, this SOA was based on the performance in the previous block so that approximately $50 \%$ inhibitions were made. Furthermore, in experimental blocks, the exact onset of the stop signal was varied between $99 \mathrm{~ms}$ above and $99 \mathrm{~ms}$ below the average SOA. The minimum average SOA was fixed at $250 \mathrm{~ms}$. If participants made less than $40 \%$ inhibitions in stop signal blocks, they were instructed to react slightly slower to the go stimuli. Trials in stop signal blocks were randomized pseudorandomly so that no more than three stop signals would be presented in succession. The difference between the posttest and pretest was that for the posttest, the base stop block was followed by three experimental blocks (equal to the pretest in terms of stimulus-response assignment) after which the stimulus-response assignment switched and another four stop signal blocks (base plus experimental blocks) were presented. Block order in terms of stimulus-response assignment was counterbalanced across participants.

\section{Motoric parameters}

Motor disturbances under haloperidol are related to dopamine receptor occupancy; specifically, extrapyramidal symptoms or akathisia occur with $>78-80 \%$ receptor occupancy (Nyberg et al. 1995; Kapur et al. 2000). Studies show that akathisia can occur after a single dose of haloperidol (Kumari et al. 1997; Kumari et al. 1999; Zirnheld et al. 2004; Saeedi et al. 2006). Importantly, the effect of haloperidol on motor activity may be used as an index for individual responsivity under the assumption that a drug-induced motor effect is positively correlated with the central effect. Firstly, haloperidol-induced akathisia/ dyskinesia, resulting in possible increases in motor activity, was assessed by using an Actigraph (Actigraph GT3X+, Actigraph, LLC; Pensacola, FL, USA); for application of actometry in a more clinically oriented setting, see Janno et al. (2008). The actigraph stores acceleration data (in gravitational unit $\mathrm{G}$ ) with a sample rate of $100 \mathrm{~Hz}$.

Secondly, haloperidol-induced bradykinesia has been proposed to be reflected in a decrease in velocity scaling. Here, velocity scaling was assessed by presenting a target first at the center of a computer screen. On a first trial, it subsequently moved either $25^{\circ}$ or $45^{\circ}$ from the center starting point, after which it returned to the center. Participants were instructed to move a cursor as quickly and accurately as possible to the location of the target by flexing a handle by means of wrist rotation. The target always remained at a location for $2 \mathrm{~s}$. In each block, the target movement from center to periphery was repeated 32 times (16 times for $25^{\circ}$ and 16 times for $45^{\circ}$, randomly). The task consisted of four blocks: two in which the target always moved from the center to the left and subjects used their right hand to correspondingly move the cursor and two in which the target always moved from the center to the right and subjects used their left hand to correspondingly move the cursor.

\section{Cardiovascular and subjective parameters}

Cardiovascular variables (diastolic and systolic blood pressure and heart rate) were assessed by using an automatic blood pressure monitor (Microlife, BP3AC1-1PC). Subjective effects were assessed by using the Profile of Mood States (POMS) questionnaire (Wald 1984; Wald and Mellenbergh 1990).

\section{Procedure}

A repeated-measures placebo-controlled crossover design was used. Participants performed in two sessions: drug (haloperidol) and placebo. Sessions were separated by at least 1 week. The specific order of the sessions (drug/placebo) as well as the order of computer tasks was counterbalanced over participants. After participants signed the informed consent and passed the medical interview, the actigraph was placed on the right ankle. The actigraph collected acceleration data along three axes during the entire experiment. Participants filled out the POMS questionnaire and performed for about 10 min the velocity scaling task. Subsequently, participants performed the pretest version of the SST and VSC which took approximately $30 \mathrm{~min}$. Approximately $10 \mathrm{~min}$ prior to drug administration, blood pressure and heart rate were assessed. About $1 \mathrm{~h}$ and $50 \mathrm{~min}$ after drug administration $(t=1 \mathrm{~h}$ $50 \mathrm{~min}$ ), an EEG cap was placed (EEG data presented elsewhere) and electrodes were placed at the outer canthi and supraorbitally and infraorbitally to the eye to record eye movements (horizontal electrooculogram (HEOG) and vertical electrooculogram (VEOG), respectively). At $t=2 \mathrm{~h} 45 \mathrm{~min}$, participants filled out the POMS again; 5 min later, cardiovascular variables were assessed, and at $t=3 \mathrm{~h} 00 \mathrm{~min}$, 
participants performed the posttest version of the VSC task and SST. Between blocks, participants had short breaks, and between tasks, there was room for a longer break (20 min). Upon completion of both tasks, velocity scaling was assessed again (at $t=5 \mathrm{~h} 20 \mathrm{~min}$ ), and at $t=5 \mathrm{~h} 30 \mathrm{~min}$, blood pressure and heart rate were measured. The total duration of the experiment was approximately $6.5 \mathrm{~h}$.

\section{Data analyses}

\section{Motor activity}

Baseline assessment (T1) was at 10 min after the start of the first pretreatment computer task (VSC or SST). Posttreatment assessment (T2) was at $10 \mathrm{~min}$ after the start of the first posttreatment computer task (VSC or SST). T1 and T2 consisted of a 10 min recording with a sample rate of $100 \mathrm{~Hz}$. For analyses, per condition, 10-s epochs of acceleration data per axis (in total three axes) was averaged across axes and over $10 \mathrm{~min}$ recording to yield one measure of motor activity.

\section{Velocity scaling}

Velocity scaling values are expressed in degrees/s/degree (Caligiuri et al. 1998). Scaling values for movements toward targets were averaged with values for return movements.

\section{POMS}

The POMS questionnaire consists of six scales: depression (eight items), anger (seven items), vigor (five items), fatigue (six items), tension (six items), and total mood disturbance. Each scale ranges from 0 to 4 . The total score on a scale was determined by the sum of the item values for that scale.

\section{Stop signal task}

In line with de Jong et al. (1990), the SSRT was calculated by using the integration method. This method minimizes the bias of SSRT estimation related to variation in go RT (Verbruggen et al. 2013). To correct stop rates for go-omission rate, following Tannock et al. (1989), the corrected proportion of successful stops was calculated as proportion of inhibitions - (proportion of omissions $\times$ proportion of inhibitions $) /(1-$ (proportion of omissions $\times$ proportion of inhibitions)).

Subsequently, RTs in go trials in the 150 to 1500 -ms window were ordered from short to long RTs. The $n$th point on this vector was determined by multiplying the total number of RTs by one minus the stop rate (corrected for omissions). The SSRT was then calculated by subtracting the average go-stop interval from the reaction time at the $n$th point on the RT vector.

\section{Visual spatial cueing task}

Reaction times within the 100-1500 ms range were considered valid and were included in the analyses. For each participant, session and time (pre/post) and reaction times on (separately) valid trials and invalid trials were averaged across blocks. The validity effect was calculated as the difference between the averaged reaction time on invalidly cued targets minus validly cued targets. Horizontal saccades were monitored via HEOG. We defined a saccade as a peak (positive or negative polarity) exceeding $60 \mu \mathrm{V}$ relative to baseline (van der Lubbe et al. 2006). Performance data was not corrected for HEOG activity, but VSC performance analyses were rerun excluding participants that showed excessive saccades (saccades in $>85 \%$ of trials).

Responses are in general faster and more accurate when the stimulus requires a response from the spatially corresponding hand (congruent condition); this is called the Simon effect (Simon and Wolf 1963). Following the suggestion of one of the reviewers, the interaction between drug and Simon congruency was analyzed post hoc.

\section{Statistical analyses}

Analyses of variances (ANOVAs) were used. Alpha was set at 0.05 . With respect to the POMS, data were missing from one subject. With respect to the actigraph data, one participant was excluded for the analysis of motor activity because of a recording error. Secondary analyses were also performed. To account for individual differences in drug responsivity, correlations were calculated between the drug effect on motoric parameters on one hand and the performance variables on the other. Furthermore, the drug effect on performance variables was also assessed for the split-half sample that showed the strongest drug effect on velocity scaling and the split-half sample that showed the strongest drug effect on motor activity.

\section{Results}

\section{Cardiovascular data}

Haloperidol did not affect heart rate and systolic or diastolic blood pressure $(F(1,27)<1$ for all drug $\times$ time interactions $)$.

\section{Subjective effects}

None of the variables (depression, anger, vigor, fatigue, tension, and total mood disturbance) on the POMS scale were affected by haloperidol. 

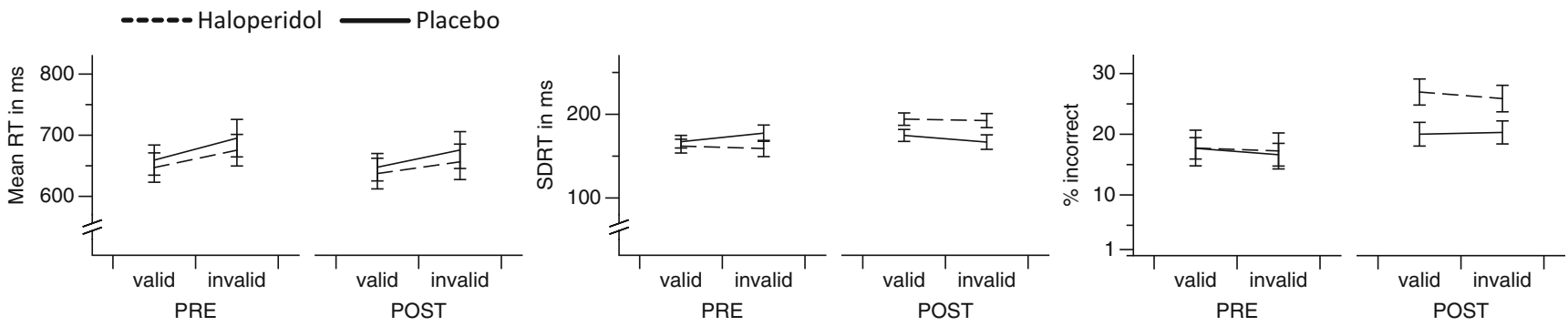

Fig. 1 Performance data in the VSC task (means and standard error bars) before (PRE) and after (POST) haloperidol and placebo administration, respectively

\section{Performance data}

\section{Visual spatial cueing task}

Performance data in the VSC task are depicted in Fig. 1. RT was shorter for validly cued targets as opposed to invalidly cued targets (main effect of validity, $F(1,27)=13.6$, $p=0.001$ ). Errors and RT variability (standard deviation of reaction time (SDRT)) were not affected by cueing (both, $F(1$, $27)<1)$. Haloperidol did not affect the validity effect on RT; the time $\times$ drug $\times$ validity interaction was not significant $(F(1$, $27)<1)$. Three participants showed excessive saccades ( $>85 \%$ of trials). Exclusion of these participants did not yield a different result with respect to latter interaction. Haloperidol resulted in a general increase in errors and SDRT, as evident in a time $\times$ drug interaction (respectively, $F(1,27)=4.5$, $p=0.043, F(1,27)=12.2, p=0.002)$. Mean RT was not affected by haloperidol (time $\times$ drug interaction, $F(1,27)<1$ ).

For the post hoc analysis pertaining to the Simon effect, the factor congruency was added to the analysis, which logically resulted in a relatively smaller number of trials per condition.

Fig. 2 Performance data in the SST (means and standard error bars) before (PRE) and after (POST) haloperidol and placebo administration, respectively
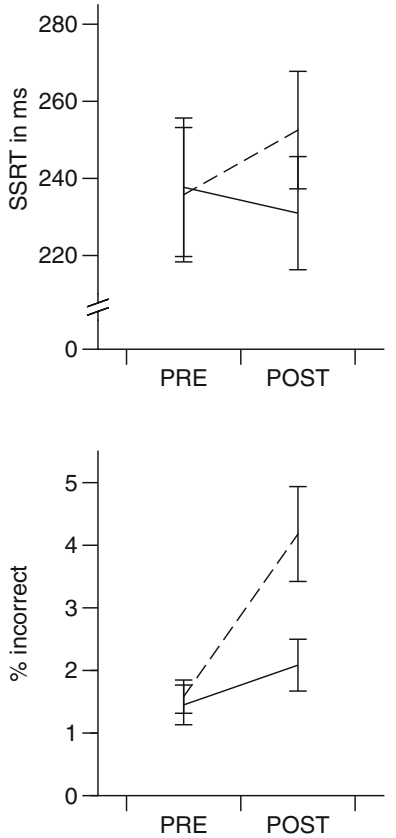

For one participant, this yielded an insufficient number of trials $(<5)$ for the invalidly cued incongruent and congruent target conditions in the pretest. This participant was excluded from the post hoc analysis. In the congruent, compared to the incongruent condition, RTs were shorter and fewer errors were made (main effect of congruency, respectively, $F(1$, 26) $=17.37, p<0.001 ; F(1,26)=5.75, p=0.024$. However, there were no interactions between the drug effects and the effect of congruency.

\section{Stop signal task}

Performance data in the SST are depicted in Fig. 2. Haloperidol resulted in an increase in SSRT, SDRT, percentage incorrect responses, and percentage of omissions relative to placebo as indicated by significant time $\times$ drug interactions $(F(1,27)=5.101, p=0.032, F(1,27)=10.2, p=0.004, F(1$, $27)=13.1, p=0.001, F(1,27)=5.5, p=0.027$, respectively). Mean reaction time was not significantly affected by haloperidol $(F(1,27)<1)$. Table 1 shows the percentages of successful inhibition (corrected for omissions).
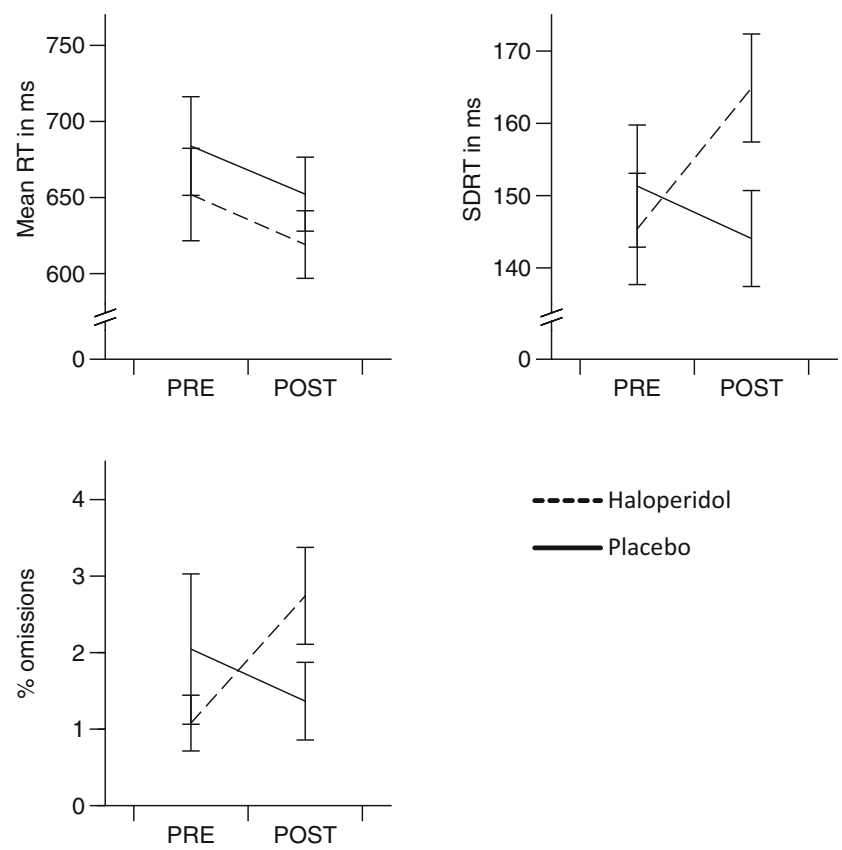
Table 1 Percentage of inhibition (corrected for omissions) in the SST, per session (drug/placebo), pre and post treatment

\begin{tabular}{lll}
\hline & Pre & Post \\
& $M(\mathrm{SD})$ & $M(\mathrm{SD})$ \\
\hline Placebo & $53 \%(11)$ & $48 \%(10)$ \\
Haloperidol & $47 \%(12)$ & $44 \%(12)$ \\
\hline
\end{tabular}

\section{Motor effects}

As depicted in Fig. 3 (top left panel), there was a trend toward a significant time $\times$ drug interaction with respect to motor activity $(F(1,26)=3.7, p=0.064)$. It is clear that the standard error is sizeable in the posttreatment condition under haloperidol. Evaluation of potential outliers per condition (placebo/ haloperidol) and time point (pre/post) indicated several outliers, defined as values exceeding three standard deviations from the mean within the specific condition. Participants for which any such outlier was evident in any of the four conditions were excluded $(N=5)$ from the second analysis (Fig. 3, right panel). This analysis indicated a significant increase in motor activity after haloperidol relative to placebo (significant drug $\times$ time interaction, $F(1,21)=11.881, p=0.002)$.

Velocity scaling was unaffected by time and by its interaction with drug (Fig. 3, bottom panel). One outlier (STD > 3) was present in one condition. Again, no significant time $\times$ drug interaction was present after the exclusion of this participant.
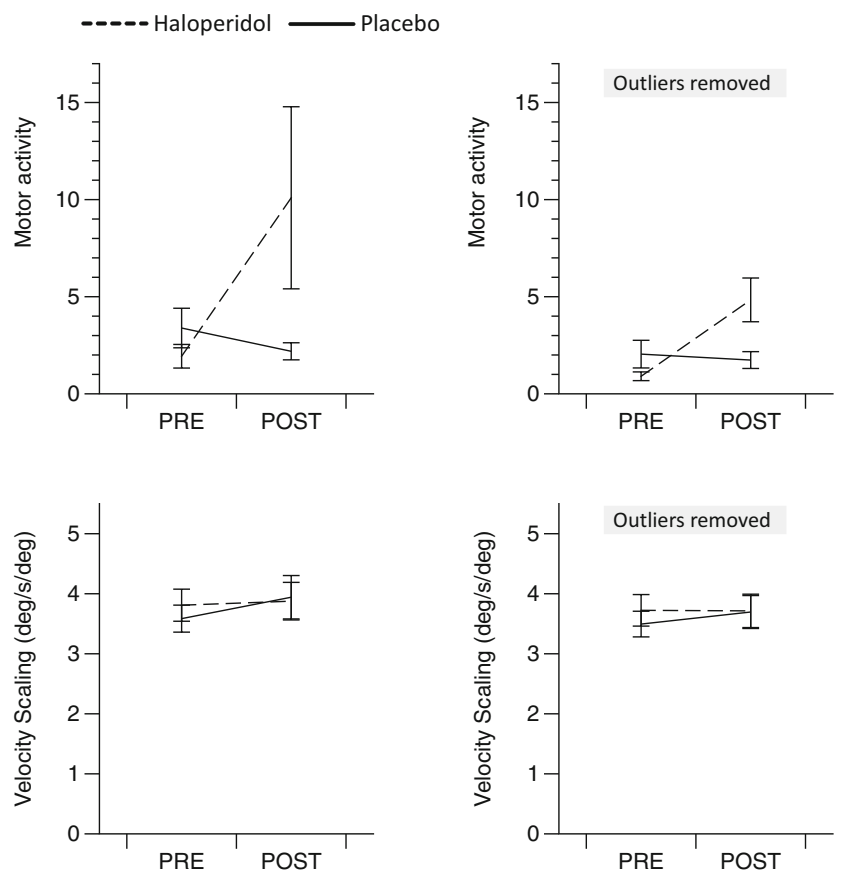

Fig. 3 Motor activity (top panel, accumulated G (10 min), mean G per $10 \mathrm{~s}$, collapsed over axes)) and velocity scaling (bottom panel, degrees/s/ degree) before and after placebo and haloperidol administration and separately for whole-sample analysis and analysis of the sample from which participants with outliers have been excluded

\section{Individual differences}

There was no correlation between the drug effect on motoric parameters and neurocognitive variables. Results of the splithalf analyses did not yield notable additional significant effects. These analyses also did not reveal a significant drug effect on the validity effect in the VSC.

\section{Discussion}

In the current study, the role of dopamine in visuospatial attention and inhibition was investigated, using $2 \mathrm{mg}$ haloperidol to attenuate dopaminergic neurotransmission. In line with the hypothesis, haloperidol negatively affected inhibition as indexed by SSRT. Surprisingly, haloperidol did not affect disengagement or bias as evident by the lack of effect on the validity effect in the VSC task.

The lack of a reduction of the validity effect under haloperidol is inconsistent with the results of Clark et al. (1989). The current dose may have been insufficient, or individual variability with respect to the drug response may have been sizeable. To account for this, the drug effect on motor activity was used as an index for central drug responsivity. However, this approach did not yield a different outcome. Although we did account for individual variability in drug responsivity, we cannot discount the possibility that the current dosage was insufficient. One limitation of the current study was the absence of neutral cues. This would have rendered the performance data in the VSC task more informative as direct contrasts between responses on valid versus neutral and invalid versus neutral trials could have been analyzed. In the current experiment, if the expected reduction of the validity effect was evident, this (although unlikely) could in principle also imply enhanced disengagement as opposed to diminished bias. However, results do not support an effect on either bias or disengagement, since no effect on the validity effect and no effect on mean response time in both the VSC task and the SST were evidenced.

We proposed that there is (conceptual) overlap between mechanisms of disengagement and inhibition. Although, as noted in the introduction, there is preliminary evidence supporting this claim, conclusive data is still lacking. It must be noted that post hoc preliminary data (available upon request) did not show a significant correlation between the (in)validity effect and SSRT prior to the drug challenge, which might indicate a lack of association between inhibition and disengagement of attention as reflected by SSRT and RTs to invalidly cued targets, respectively. However, as pointed out, the validity effect reflects a mix of both disengagement-related processing and bias-related processing.

Posthoc, explorative evaluation indicated that responses were faster and more accurate when the stimulus required a response from the spatially corresponding hand (congruent condition), also called the Simon effect (Simon and Wolf 1963). The 
Simon effect can be seen as reflecting selective impulse suppression, in contrast to more general inhibition as indexed by SSRT (Ramdani et al. 2015). In the latter study, it was shown that the Simon effect may be affected by dopamine depletion. However, in the current study, we did not find an interaction between the effect of haloperidol and that of congruency. It has been shown that the effect of dopaminergic challenge on the effect of congruency depends on response latency (Ramdani et al. 2015). Hence, it is plausible that haloperidol did not affect congruency in the current experiment, because we did not assess the drug effect on the congruency effect as a function of response latency (as this would yield an insufficient number of trials).

Haloperidol affected SSRT in the SST, and this result may have ramifications for the understanding of the effects of methylphenidate, a widely used drug in the treatment of ADHD with effects primarily not only on dopaminergic but also on the noradrenergic neurotransmission. Methylphenidate has been reported to reduce SSRT in both patients (Aron et al. 2003; Lijffijt et al. 2006; Overtoom et al. 2009) and healthy volunteers (Nandam et al. 2011). In our earlier study, however, it was shown that SSRT was unaffected by noradrenergic antagonism by clonidine (Logemann et al. 2013). Methylphenidateinduced modulation of SSRT may reflect the modulation of a dopaminergic rather than of a noradrenergic mechanism. This is also consistent with the results from Lijffijt et al. (2006).

It should be noted that relatively recently, it has been reported that SSRTs can become biased as a result of effects on general response time (Verbruggen et al. 2013). This bias is significantly reduced or absent by using the integration approach in the calculation of the SSRT as opposed to the mean method. In the current study, the effect of haloperidol on SSRT cannot plausibly be related to effects on mean RT. Firstly, the integration method was used for the analysis of SSRTs. Secondly, in both the VSC task and SST, haloperidol did not significantly affect mean RT.

The slower processing of the stop stimulus (as indexed by SSRT) does not have to be specific to inhibition (Bekker et al. 2005). It could potentially indicate a general slower accumulation of information. However, there was no evidence of a concurrent increase in reaction time, discounting an interpretation of increased SSRT in terms of general slowed accumulation of information. In a related vein, the increase in error rate, which often is interpreted in terms of lapses of attention (Castellanos and Tannock 2002), may indicate premature responding in the context of a lack of a concurrent increase in RT (Bekker et al. 2005).

Haloperidol resulted in increased reaction variability (SDRT) in both tasks. In addition, in the stop task, goomission rates were higher under haloperidol. These effects reflect an increased number of lapses of attention, resulting in a higher incidence of missed targets or delayed responses, the latter resulting in higher RT variability. Note that this is not easily related to general sedation, as haloperidol did not affect subjective measures, cardiovascular variables, or general reaction time.
It should be stressed that potential session order effects were taken into account a priori by using counterbalancing and by inclusion of the pretest. Furthermore, potential session order effects pertaining to the primary variables/interactions of interest in the SST and VSC task were explored post hoc. Specifically, for the SST variables, the drug $\times$ time $\times$ order interactions were not significant, and for the VSC task variables, the drug $\times$ time $\times$ validity $\times$ order interactions were also not significant.

Lastly, motor activity increased under haloperidol which may reflect extrapyramidal symptoms or akathisia (Nyberg et al. 1995; Kapur et al. 2000). Akathisia is not a likely explanation of the haloperidol-induced increase of motor activity. Post hoc analyses (not shown, but available upon request) did not indicate an effect of haloperidol on the item coding for "restlessness" of the POMS questionnaire. Furthermore, there was no correlation between the haloperidol-induced effect on motor activity and a potential subtle haloperidol-induced effect on restlessness as assessed by the relevant item of the POMS.

Velocity scaling was unaffected by haloperidol. Neuromotor retardation as reflected in (reduced) velocity scaling has been reported in patients with Parkinson (Caligiuri et al. 1998). It may be that attenuation of dopaminergic neurotransmission in the current study was not sufficient to render bradykinesia as robust as in Parkinson's.

It must be noted that haloperidol also blocks the alpha-1 adrenoreceptor (Richelson and Nelson 1984; Leysen et al. 1992; Kroeze et al. 2003). Although the exact role in cognitive processing is yet to be firmly established, scarce animal studies suggest that blockage of the alpha-1 receptor may actually benefit prefrontal cortex functioning (Arnsten et al. 1999; Arnsten 2004). Hence, if the latter results generalize to human subjects, the haloperidolinduced detrimental effects on cognitive performance are not likely a result of blockage of alpha-1 adrenoreceptors.

To conclude, haloperidol negatively affected inhibitory motor control, but there were no indications of effects on bias or disengagement in the VSC task. It may well be that disengagement is subserved by a different neurotransmitter system as opposed to inhibitory motor control. On the other hand, the dose may have been insufficient to affect bias and disengagement in the VSC task, especially in light of previous work.

\section{Compliance with ethical standards}

Conflict of interest There is no conflict of interest to disclose.

\section{References}

Arnsten AFT (2004) Adrenergic targets for the treatment of cognitive deficits in schizophrenia. Psychopharmacology 174:25-31. doi:10.1007/s00213-003-1724-3

Arnsten AF, Mathew R, Ubriani R et al (1999) Alpha-1 noradrenergic receptor stimulation impairs prefrontal cortical cognitive function. Biol Psychiatry 45:26-31 
Aron AR, Fletcher PC, Bullmore ET et al (2003) Stop-signal inhibition disrupted by damage to right inferior frontal gyrus in humans. Nat Neurosci 6:115-116. doi:10.1038/nn1003

Aron AR, Robbins TW, Poldrack RA (2014) Inhibition and the right inferior frontal cortex: one decade on. Trends Cogn Sci 18:177185. doi:10.1016/j.tics.2013.12.003

Bari A, Robbins TW (2013) Noradrenergic versus dopaminergic modulation of impulsivity, attention and monitoring behaviour in rats performing the stop-signal task: possible relevance to ADHD. Psychopharmacology 230:89-111. doi:10.1007/s00213-013-3141-6

Bari A, Eagle DM, Mar AC et al (2009) Dissociable effects of noradrenaline, dopamine, and serotonin uptake blockade on stop task performance in rats. Psychopharmacology 205:273-283. doi:10.1007/s00213-009$1537-0$

Bekker EM, Overtoom CC, Kenemans JL et al (2005) Stopping and changing in adults with ADHD. Psychol Med 35:807-816

Caligiuri MP, Lohr JB, Ruck RK (1998) Scaling of movement velocity: a measure of neuromotor retardation in individuals with psychopathology. Psychophysiology 35:431-437

Castellanos FX, Tannock R (2002) Neuroscience of attention-deficit/hyperactivity disorder: the search for endophenotypes. Nat Rev Neurosci 3:617-628. doi:10.1038/nrn896

Clark CR, Geffen GM, Geffen LB (1989) Catecholamines and the covert orientation of attention in humans. Neuropsychologia 27:131-139

Colzato LS, Jongkees BJ, Sellaro R et al (2014) Eating to stop: tyrosine supplementation enhances inhibitory control but not response execution. Neuropsychologia 62:398-402. doi:10.1016/j. neuropsychologia.2013.12.027

Corbetta M, Shulman GL (2002) Control of goal-directed and stimulusdriven attention in the brain. Nat Rev Neurosci 3:201-215. doi:10.1038/nrn 755

Corbetta M, Patel G, Shulman GL (2008) The reorienting system of the human brain: from environment to theory of mind. Neuron 58:306324. doi:10.1016/j.neuron.2008.04.017

Coull JT, Nobre AC, Frith CD (2001) The noradrenergic alpha2 agonist clonidine modulates behavioural and neuroanatomical correlates of human attentional orienting and alerting. Cereb Cortex N Y N 11:73-841991

de Jong R, Coles MG, Logan GD, Gratton G (1990) In search of the point of no return: the control of response processes. J Exp Psychol Hum Percept Perform 16:164-182. doi:10.1037/0096-1523.16.1.164

De Jong R, Coles MG, Logan GD (1995) Strategies and mechanisms in nonselective and selective inhibitory motor control. J Exp Psychol Hum Percept Perform 21:498-511

Eagle DM, Wong JCK, Allan ME et al (2011) Contrasting roles for dopamine D1 and D2 receptor subtypes in the dorsomedial striatum but not the nucleus accumbens core during behavioral inhibition in the stop-signal task in rats. J Neurosci 31:7349-7356. doi:10.1523/JNEUROSCI.618210.2011

Ghahremani DG, Lee B, Robertson CL et al (2012) Striatal dopamine $\mathrm{D}_{2} /$ $\mathrm{D}_{3}$ receptors mediate response inhibition and related activity in frontostriatal neural circuitry in humans. J Neurosci 32:73167324. doi:10.1523/JNEUROSCI.4284-11.2012

Gurvich CT, Rossell SL (2014) Genetic variations in dopamine and inhibitory control: lack of influence on action restraint. Behav Brain Res 267:12-16. doi:10.1016/j.bbr.2014.03.015

Janno S, Holi MM, Tuisku K, Wahlbeck K (2008) Neuroleptic-induced movement disorders in a naturalistic schizophrenia population: diagnostic value of actometric movement patterns. BMC Neurol 8:10. doi:10.1186/1471-2377-8-10

Kapur S, Zipursky R, Jones C et al (2000) Relationship between dopamine $D(2)$ occupancy, clinical response, and side effects: a doubleblind PET study of first-episode schizophrenia. Am J Psychiatry 157:514-520

Kenemans JL (2015) Specific proactive and generic reactive inhibition. Neurosci Biobehav Rev 56:115-126. doi:10.1016/j. neubiorev.2015.06.011
Kenemans JL, Kähkönen S (2011) How human electrophysiology informs psychopharmacology: from bottom-up driven processing to top-down control. Neuropsychopharmacol Off Publ Am Coll Neuropsychopharmacol 36:26-51. doi:10.1038/npp.2010.157

Kenemans JL, Bekker EM, Lijffijt M et al (2005) Attention deficit and impulsivity: selecting, shifting, and stopping. Int J Psychophysiol 58:59-70. doi:10.1016/j.ijpsycho.2005.03.009

Kroeze WK, Hufeisen SJ, Popadak BA et al (2003) H1-histamine receptor affinity predicts short-term weight gain for typical and atypical antipsychotic drugs. Neuropsychopharmacol Off Publ Am Coll Neuropsychopharmacol 28:519-526. doi:10.1038/sj.npp.1300027

Kumari V, Corr PJ, Mulligan OF et al (1997) Effects of acute administration of d-amphetamine and haloperidol on procedural learning in man. Psychopharmacology 129:271-276

Kumari V, Cotter PA, Mulligan OF et al (1999) Effects of d-amphetamine and haloperidol on latent inhibition in healthy male volunteers. J Psychopharmacol Oxf Engl 13:398-405

Lansbergen MM, Böcker KBE, Bekker EM, Kenemans JL (2007) Neural correlates of stopping and self-reported impulsivity. Clin Neurophysiol Off J Int Fed Clin Neurophysiol 118:2089-2103. doi:10.1016/j.clinph.2007.06.011

Leysen JE, Janssen PM, Gommeren W et al (1992) In vitro and in vivo receptor binding and effects on monoamine turnover in rat brain regions of the novel antipsychotics risperidone and ocaperidone. Mol Pharmacol 41:494-508

Lijffijt M, Kenemans JL, ter Wal A et al (2006) Dose-related effect of methylphenidate on stopping and changing in children with attention-deficit/hyperactivity disorder. Eur Psychiatry J Assoc Eur Psychiatr 21:544-547. doi:10.1016/j.eurpsy.2005.04.003

Logan GD, Cowan WB, Davis KA (1984) On the ability to inhibit simple and choice reaction time responses: a model and a method. J Exp Psychol Hum Percept Perform 10:276-291

Logemann HNA, Böcker KBE, Deschamps PKH et al (2013) The effect of noradrenergic attenuation by clonidine on inhibition in the stop signal task. Pharmacol Biochem Behav 110:104-111. doi:10.1016/j. pbb.2013.06.007

Logemann HNA, Böcker KBE, Deschamps PKH et al (2014) The effect of attenuating noradrenergic neurotransmission by clonidine on brain activity measures of visuospatial attention. Hum Psychopharmacol Clin Exp 29:46-54. doi:10.1002/hup.2367

Mangun GR, Hillyard SA (1991) Modulations of sensory-evoked brain potentials indicate changes in perceptual processing during visualspatial priming. J Exp Psychol Hum Percept Perform 17:10571074. doi:10.1037/0096-1523.17.4.1057

Meinke A, Thiel CM, Fink GR (2006) Effects of nicotine on visuo-spatial selective attention as indexed by event-related potentials. Neuroscience 141:201-212. doi:10.1016/j.neuroscience.2006.03.072

Nandam LS, Hester R, Wagner J et al (2011) Methylphenidate but not atomoxetine or citalopram modulates inhibitory control and response time variability. Biol Psychiatry 69:902-904. doi:10.1016/j. biopsych.2010.11.014

Nyberg S, Nordström AL, Halldin C, Farde L (1995) Positron emission tomography studies on D2 dopamine receptor occupancy and plasma antipsychotic drug levels in man. Int Clin Psychopharmacol 10(Suppl 3):81-85

Overtoom CCE, Bekker EM, van der Molen MW et al (2009) Methylphenidate restores link between stop-signal sensory impact and successful stopping in adults with attention-deficit/hyperactivity disorder. Biol Psychiatry 65:614-619. doi:10.1016/j. biopsych.2008.10.048

Posner MI, Snyder CR, Davidson BJ (1980) Attention and the detection of signals. J Exp Psychol 109:160-174

Potter AS, Bucci DJ, Newhouse PA (2012) Manipulation of nicotinic acetylcholine receptors differentially affects behavioral inhibition in human subjects with and without disordered baseline impulsivity. 
Psychopharmacology 220:331-340. doi:10.1007/s00213-0112476-0

Ramdani C, Carbonnell L, Vidal F, Béranger C, Dagher A, Hasbroucq T (2015) Dopamine precursors depletion impairs impulse control in healthy volunteers. Psychopharmacology 232(2):477-487

Richelson E, Nelson A (1984) Antagonism by neuroleptics of neurotransmitter receptors of normal human brain in vitro. Eur $\mathrm{J}$ Pharmacol 103:197-204

Saeedi H, Remington G, Christensen BK (2006) Impact of haloperidol, a dopamine D2 antagonist, on cognition and mood. Schizophr Res 85: 222-231. doi:10.1016/j.schres.2006.03.033

Schmajuk M, Liotti M, Busse L, Woldorff MG (2006) Electrophysiological activity underlying inhibitory control processes in normal adults. Neuropsychologia 44:384-395. doi:10.1016/j. neuropsychologia.2005.06.005

Schotte A, Janssen PF, Gommeren W et al (1996) Risperidone compared with new and reference antipsychotic drugs: in vitro and in vivo receptor binding. Psychopharmacology 124:57-73

Simon JR, Wolf JD (1963) Choice reaction time as a function of angular stimulus-response correspondence and age. Ergonomics 6(1):99105

Tannock R, Schachar RJ, Carr RP, Chajczyk D, Logan GD (1989) Effects of methylphenidate on inhibitory control in hyperactive children. J Abnorm Child Psychol 17(5):473-491

Thiel CM, Fink GR (2008) Effects of the cholinergic agonist nicotine on reorienting of visual spatial attention and top-down attentional control. Neuroscience 152:381-390. doi:10.1016/j.neuroscience.2007.10.061

Thiel CM, Zilles K, Fink GR (2005) Nicotine modulates reorienting of visuospatial attention and neural activity in human parietal cortex.
Neuropsychopharmacol Off Publ Am Coll Neuropsychopharmacol 30:810-820. doi:10.1038/sj.npp.1300633

van der Lubbe RHJ, Neggers SFW, Verleger R, Kenemans JL (2006) Spatiotemporal overlap between brain activation related to saccade preparation and attentional orienting. Brain Res 1072:133-152. doi:10.1016/j.brainres.2005.11.087

Verbruggen F, Chambers CD, Logan GD (2013) Fictitious inhibitory differences: how skewness and slowing distort the estimation of stopping latencies. Psychol Sci 24:352-362. doi:10.1177 /0956797612457390

Volkow ND, Wang G-J, Kollins SH et al (2009) Evaluating dopamine reward pathway in ADHD: clinical implications. JAMA 302:10841091. doi:10.1001/jama.2009.1308

Vossel S, Thiel CM, Fink GR (2008) Behavioral and neural effects of nicotine on visuospatial attentional reorienting in non-smoking subjects. Neuropsychopharmacol Off Publ Am Coll Neuropsychopharmacol 33:731-738. doi:10.1038/sj.npp.1301469

Wald, F.D.M. (1984) De verkorte POMS. Master's thesis.

Wald FDM, Mellenbergh GJ (1990) Instrumenteel onderzoek. Ned Tijdschr Voor Psychol 45:86-90

Witte EA, Davidson MC, Marrocco RT (1997) Effects of altering brain cholinergic activity on covert orienting of attention: comparison of monkey and human performance. Psychopharmacology 132:324-334

Zetterström T, Sharp T, Collin AK, Ungerstedt U (1988) In vivo measurement of extracellular dopamine and DOPAC in rat striatum after various dopamine-releasing drugs; implications for the origin of extracellular DOPAC. Eur J Pharmacol 148:327-334

Zirnheld PJ, Carroll CA, Kieffaber PD et al (2004) Haloperidol impairs learning and error-related negativity in humans. J Cogn Neurosci 16: 1098-1112. doi:10.1162/0898929041502779 